\title{
A Comparative Case Study of Electric Utility Companies' Use of Energy Democracy in Strategic Communication
}

\author{
Meaghan McKasy* and Sara K. Yeo \\ Department of Communication, University of Utah, Salt Lake City, UT, United States
}

\section{OPEN ACCESS}

Edited by: Andrea M. Feldpausch-Parker, State University of New York College of Environmental Science and

Forestry, United States

Reviewed by:

Bruno Takahashi,

Michigan State University,

United States

Tarla Rai Peterson,

University of Texas at El Paso,

United States

*Correspondence:

Meaghan McKasy

meaghan.mckasy@utah.edu

Specialty section:

This article was submitted to Science and Environmental

Communication,

a section of the journa

Frontiers in Communication

Received: 31 October 2017

Accepted: 12 February 2018

Published: 27 February 2018

Citation:

McKasy $M$ and Yeo SK (2018) A Comparative Case Study of Electric

Utility Companies' Use of Energy

Democracy in Strategic

Communication.

Front. Commun. 3:10.

doi: 10.3389/fcomm.2018.00010
A substantial increase in distributed renewable energy resources is changing the face of the energy environment, leading to strategic communication efforts by key stakeholders. The energy democracy movement supports this transformation from fossil fuels to distributed renewable energy and aims for equitable involvement of publics in energy decision making. These tenets challenge utility company earnings as they are directly related to energy sales and infrastructure returns on investment. Proposals by electric utility companies to restructure net-metering policies as a solution to financial issues have been criticized as prohibitive to the success of renewable energy advancement. To address these disagreements, the Edison Electric Institute and a communication firm, Maslansky \& Partners, created The Future of Energy: A Working Communication Guide for Discussion. This handbook provides utility companies with strategic communication guidelines to portray themselves as supportive of renewables within a dynamic energy industry. We posit that aspects of the energy democracy movement have been employed by electric utility companies, as shown through the use of the handbook, as a strategy for communicating with customers in discussions around net metering. We examine two case studies in states with recent controversial net-metering policy changes by analyzing utility company websites and press releases for the use of the communication handbook terminology. We found that, in both cases, the suggested language was used to position their companies as pro-renewable energy and their utility-scale projects as more equitable for their customers. In addition, we found differences between each company's use of key terms from the handbook. We posit that this is due to the temporal context of each net-metering debate at the time of the handbook release. Conclusions and future directions for research in the growing area of energy democracy are discussed.

\footnotetext{
Keywords: electricity, energy, energy democracy, net metering, strategic communication
}

A dramatic increase in solar power adoption has occurred in the last decade, in part because of the growing consumer interest in green energy, coupled with significant decreases in associated costs (Weiner, 2015; Muro and Saha, 2016). The unprecedented speed at which distributed resources are changing energy systems underscores the challenge and importance of understanding the roles of humans in this transition. This evolution is especially apparent in democratic societies in which participatory communication is integral to resolving environmental issues (Stephens et al., 2015). 
Energy democracy is a movement that aims to involve publics in energy decision making with emphasis on the transformation from fossil fuels to renewable energy and distributed systems (Fairchild, 2017). This aligns with a broader effort in environmental communication to address human-caused threats to ecological systems and the failure of social institutions to confront these threats (Cox, 2007). Some propose that scholars have a responsibility to assist in the accessibility and social understanding of these issues (Cox, 2007; Schwarze, 2007). Within environmental communication scholarship, energy democracy is a novel research arena with interdisciplinary capability (Endres et al., 2016). Thus far, research in energy democracy has painted transitions of energy systems in a positive light, citing the potential for civic change and public participation (Clarke, 2017; Stephens, 2017). Due to the complex nature of energy production, transmission, and distribution, a range of actors may use the energy democracy movement for a variety of reasons. Research in energy democracy has yet to examine actors who may perceive distributed energy as a barrier to their goals. For example, electric utility companies are disadvantaged by the increased adoption of distributed renewable energy because customers are no longer reliant on utility-sourced power.

The goal of the present work is to identify how aspects of the energy democracy movement have been employed by electric utility companies as a strategy for communicating with their customers in discussions around net metering. As prior research does not offer sufficient evidence to allow us to posit hypotheses, we instead formulate propositions. To this end, we examine utility company artifacts for use of key terms derived from a handbook that guides communication processes of electric utility companies, The Future of Energy: A Working Communication Guide for Discussion. Using case studies of NV Energy and Rocky Mountain Power (RMP), we conduct a qualitative analysis of websites and press releases about net metering and identify the use of handbook language in these communications. In the following sections, as background for our analysis, we describe the energy democracy movement and the strategic use of the handbook by NV Energy and RMP in the context of net metering.

\section{BACKGROUND}

\section{Energy Democracy as a Communication Strategy}

Though currently centrally managed and regulated, energy systems in the USA are increasingly moving toward alternative, renewable energies. Renewable energy has been conceptualized as decarbonized, decentralized, and democratized (Pezzullo, 2017). However, there is no assumption of democracy or justice within the transition of energy systems. Attempts to integrate energy matters with social issues and public participation have led to the development of the energy democracy movement (Endres et al., 2016), which calls for democratic participatory communication and broader civic engagement in energy systems change (Stephens, 2017). Social justice and public engagement are key to the democratic ideal of voice, trust, and decision legitimacy (Clarke, 2017). Within the energy democracy movement, energy consumers are "prosumers" who participate in decisions throughout the energy process, from production to consumption (Giancatarino, 2012). The community of Boulder, Colorado, is an example of the energy democracy movement in the public sphere. In 2016, the city published a Climate Action Plan with aims to municipalize their energy and deliberately involve citizen voices in the energy shift (Pezzullo, 2017). By making citizens a part of the democratic process regardless of their financial, social, or physical role in the community, Boulder fulfills the key social justice aspect of the energy democracy movement.

While still in its infancy, one main goal of the energy democracy movement is to identify theoretical, empirical, and practical research directions. One possible direction for scholarship in this area is to address the theoretical gap between strategic communication and the energy democracy movement, which includes examining the potential negative outcomes of employing the principles of this movement as a communication strategy. Strategic communication analyzes how organizations intentionally communicate to attain designated goals (Holtzhausen, 2008). It first identifies an issue and key stakeholders that inform the subsequent creation of an organizational plan with measurable objectives (Toth, 1986; Botan, 1997; Barwick et al., 2014). These plans use messages and symbols to communicate values (Rokeach, 1968; Miller and Lellis, 2016) since the aim of strategic communication is to create a favorable reputation for stakeholders or to motivate change beneficial to the industry (Cornelissen and Cornelissen, 2017). These actions are often employed in persuasive campaigns for public relations and advertising (Bostdorff and Vibbert, 1994). For example, strategic communication is reflected in climate change mobilization through agenda-building, framing, and social marketing (Cox, 2010). In addition to civic engagement analysis, strategic and environmental communication coalesce in studies of fracking extraction (Matz and Renfrew, 2015), fossil fuel advocacy (Miller and Lellis, 2016), and corporate use of environmental rhetoric (Hanan, 2013).

Strategic communication is also used in preparation and response strategies for crisis situations (Coombs, 2015). Corporations can adopt an anticipatory model of crisis communication to prepare for environmental catastrophes (Olaniran and Williams, 2008), emphasize common societal values shared with its customers (Miller and Lellis, 2016), or systematically discredit perceived industry opposition (Faber, 2008; Bell and York, 2010; Matz and Renfrew, 2015). One of the primary foci of crisis communication is the notion that organizations can repair damaged reputations (Avery et al., 2010), and image restoration theory ${ }^{1}$ specifically addresses this strategic action (Liu and Fraustino, 2014). Image restoration theory proposes that an organization or an individual accused of being responsible for an offensive action must respond to that action (Benoit, 1997). An organization has numerous message options that they may use to address a damaged image. The five broad categories of repair are denial, evasion of responsibility, reducing offensiveness, corrective action, and

${ }^{1}$ Some scholars use the name image repair theory, as restoration suggests that the image reverts back to the original, which is often not the case when faced with a crisis (Benoit, 2000). 
mortification (Benoit, 1997). In expressing denial, an organization insists that the action never happened or that they did not have a role in it, while evading responsibility either justifies actions or downplays involvement. Reducing offensiveness can be achieved through many strategies, including minimization or bolstering. If an organization acknowledges their role in the crisis, corrective action attempts to improve the situation, while mortification involves an organization asking for forgiveness (Burns and Bruner, 2000). Due to the extent and flexibility of these categories, image restoration theory is an exhaustive approach to achieving goals through discourse (Burns and Bruner, 2000).

Ideally, democratic communication is accessible to all. However, corporate discourse is constrained and hidden from public view (Sproule, 1988). Therefore, the handbook presents a unique opportunity to publicly witness strategic image restoration in response to a crisis. An organization may use these approaches in preparation for a crisis, when analyzing a crisis, and when addressing a crisis (Benoit, 1997). Reaction to numerous environmental issues reflects image restoration theory, such as a review of British Petroleum communications after the Deepwater Horizon oil spill (Harlow et al., 2011) and President Bush's speeches following Hurricane Katrina (Liu, 2007). Image restoration theory strategically aligns with organizations in moments of negative publicity, since a corporation's image is not homogeneous and audience perception is critical to corporate success (Benoit, 2000; Burns and Bruner, 2000). The current transition in the energy industry could be viewed as a potential crisis due to its negative impacts on company image and financial returns on investment (ROI). Energy democracy offers a positive frame that a utility company may systematically apply in discussions about net metering. Thus, industry reactions to net metering pose an interesting context for analysis, yet no scholarship to date has examined the corporate use of the energy democracy movement as a communication strategy.

\section{Utility Companies and Net-Metering Policies}

Traditional utility companies are vertically integrated economies; typically, one corporation oversees electricity from creation to delivery (Steiner, 2000). Electricity is distributed through transmission lines to public consumers through a network called the power grid, which is maintained and operated by utility companies (Fang et al., 2012). Most of these companies are investor-owned and profits derive from investments in energy projects and subsequent ROI of electricity sales (Atkinson and Halvorsen, 1986). Therefore, new utility company power plants result in financial returns. A summary of electric utility company cost estimations found the potential for a natural monopoly for transmission and distribution of energy (Ramos-Real, 2005). When small-scale individual solar energy projects became popular in the 1980s, many utility companies proposed a system called net metering (Faden, 2000), which allows customers who produce their own energy to sell the excess back to the utility company at an agreed-upon price. Historically, the price at which energy is sold back to companies is equivalent to the cost an average customer pays to purchase electricity, known as the retail rate.
Net-metering policies were intended to decrease market barriers, such as technology expense, and increase the market penetration of solar energy (Doris et al., 2009).

Solar energy adoption has grown rapidly in the last decade at the residential, community, and utility company scale due to a decline in associated costs and an increase in enthusiasm for renewable energy (Muro and Saha, 2016). Typically, to propose changes in customer energy rates, utility companies forecast transitions in the energy market. In 2015, 27 states recommended changes to their net-metering policies, citing an increase in distributed renewable energy (Carley and Davies, 2016). Most studies of net metering find the retail rate for 1 kilowatt hour ( $\mathrm{kWh}$ ) of solar energy to be a fair price that encourages the development of distributed renewable energy (Forsyth et al., 2002; Kroposki et al., 2008; Doris et al., 2009). Yet, the results of net-metering studies are not homogeneous, partly due to inconsistent cost-benefit analyses (Muro and Saha, 2016). The social cost of carbon, the avoided construction of new power sources, health benefits, and environmental effects are factored into some, but not all, studies (Farrell, 2014). Therefore, many studies funded by utility companies contend that net metering and its associated policies harm customers who do not own residential solar energy (Rocky Mountain Power, 2016).

\section{The Communication Handbook}

The Edison Electric Institute (EEI) is an association that represents over $90 \%$ of investor-owned utility companies and advises their clients on public policy, an expanding market, and business strategy (Braithwait and Eakin, 2002). In April 2016, EEI distributed The Future of Energy: A Working Communication Guide for Discussion, a handbook produced by the communications consulting firm, Maslansky \& Partners. Utility companies distributed this text internally, and it became public information the following year. This document guides the energy communication strategies of utility companies that serve over 220 million Americans. It highlights that customers may not always approve of utility company actions concerning renewable energy and emphasizes the importance of customers' perceptions.

The Future of Energy proposes key terms that can be tactically changed to improve relations between the companies and their consumers in four key areas of insight: the basics, the future of the energy grid, leading the way on clean energy, and the fundamentals of rates (Maslansky and Partners, 2016). Within each area, the handbook suggests key concepts to adopt, as well as those from which to abstain, in communication efforts. The structure of the handbook guidelines closely follows the proposed layout for any form of strategic communication (Botan, 1997); a term currently used in energy discourse is described, followed by the recommended replacement term, its definition, why it matters, and language to "use and lose" when the suggested term is employed in public communications. In addition, the handbook emphasizes the differences between the assertions of utility companies and customers' perceptions. The handbook reiterates this process 25 times for the terms it finds most in need of change. The repetitive nature of this format reinforces the importance of strategic change to utility company messaging.

We identified three key handbook terms used in the netmetering discussion: universal, private, and private solar credits 
(often referred to as a subsidy). The handbookclassifieslarge projects funded with utility company resources as "universal solar" rather than utility-scale solar energy projects. This allows for a focus on the "ultimate benefit: solar for all" (Maslansky and Partners, 2016). To create a clear contrast with utility company solar projects, the handbook recommends "rooftop solar power" be referred to as "private solar power" and "distributed generation" be termed "private generation," emphasizing that the rooftop sources provide power only to individual homes and businesses. In addition, the handbook advises that net metering be referred to as private solar credits or subsidies, which support private solar customers.

Maslansky \& Partners recommend that the handbook be the only resource for marketing and communications to enable utility companies to have a unified voice (Maslansky and Partners, 2016). The communication plan of this handbook closely follows key tenets of strategic communication, such as creating a systematic plan (Toth, 1986; Botan, 1997) and communicating values that support an agreeable reputation through particular messages and symbols (Rokeach, 1968; Miller and Lellis, 2016). In this study, we postulate that NV Energy and RMP use The Future of Energy recommendations for strategic advancements of their reputations in the context of net metering. Therefore, we offer the following proposition:

P1: In the context of the net metering debate, NV Energy and RMP use key terms from the communication handbook to strategically position themselves as pro-renewable energy.

\section{NV Energy and RMP}

While roughly half of the states in the USA redesigned their net-metering policies in 2015, few received as much attention as the state of Nevada. Once a hotbed of solar growth, changes in net-metering policies emphasized the debate between utility and independent solar companies, and customers in this state. A large Nevada utility company, NV Energy, claimed that net metering allowed individuals with solar power to shift the financial burden of grid maintenance and control to customers without residential solar energy. A study conducted in 2014 by the Public Utility Commission of Nevada (PUCN) found no support for this and revealed that net metering provided $\$ 36$ million in benefits to all NV Energy customers (Price et al., 2014). Yet, in 2015, NV Energy implemented a net-metering policy that decreased the rate at which they would buy solar power from customers by $60 \%$ (Carley and Davies, 2016). Prior to the change, net-metering customers were compensated at the retail rate of \$0.09-\$0.11 per $\mathrm{kWh}$ for electricity generation. The new wholesale rate price of net metering was $\$ 0.03$ per $\mathrm{kWh}$. The decrease in the sale price, coupled with an increase in monthly fixed charges, reduced compensation and, consequently, motivation for customers to invest in individual solar energy systems. While the rate change was intended to apply to all net-metering customers, including those who purchased solar power systems prior to the change, heavy backlash led to NV Energy only applying the new rate of $\$ 0.03$ per kWh to consumers who installed solar power following implementation of the new rate (NV Energy, 2016c). After the policy transition, installation of new solar power systems declined by over $90 \%$ in the first quarter of 2016 (Muro and Saha, 2016). Many of the changes to net metering in Nevada occurred without public participation or input in the process, fueling social resistance.

Proposed changes to net metering in Utah with the utility company, RMP, occurred after the case in Nevada. A 2015 RMP cost-benefit analysis of solar power net metering found that the current rooftop solar power customers underpay their actual cost of service, shifting a total of about $\$ 6.5$ million each year to other residential customers. The company forecasted this amount to grow as much as $\$ 78$ million annually and an estimated $\$ 667$ million over the next 20 years (Rocky Mountain Power, 2016). However, it is important to note potential bias in this forecast, as most cost-benefit analyses show a net benefit of individual solar power to the grid due to avoiding construction of new facilities and the associated health and environmental effects (Muro and Saha, 2016). Similar to NV Energy, in 2016, RMP proposed net-metering changes to the Public Service Commission of Utah (PSCU) (Rocky Mountain Power, 2016). Negotiations between RMP, local companies, and community groups representing citizens led to a proposed settlement in August 2017, which was later passed by the PSCU (O'Donoghue, 2017). The agreement set the net-metering compensation rate at $\$ 0.09$ per $\mathrm{kWh}$ for electricity generation; however, the resulting program only included applicants through November 15, 2017. Owners of household solar installations built after that date would not receive compensation (Penrod, 2017).

Both NV Energy and RMP interacted with their customers on the topic of net metering to varying degrees of success. In these interactions, we believe that both utility companies strategically position themselves as proponents of social justice, a key tenant in the energy democracy movement, through the use of The Future of Energy. In addition, by arranging the companies as equitable in these conversations, the utility companies continue their practice of strategic communication by using messages to positively influence their reputation. Therefore, we put forward the following proposition:

P2: NV Energy and RMP use key terms and language from the communication handbook to represent utilityscale solar projects as a more equitable form of energy transition.

The temporal context of each case study relative to the release of The Future of Energy is distinct. The handbook was released after the NV Energy net-metering proposal and before that of RMP. When their net-metering policies were first passed, NV Energy received a lot of negative press. Therefore, it is likely that they used language from the handbook for damage control. In accordance with image restoration theory, NV Energy was accused of an offensive action, and it was thus necessary to address the issue in an attempt to improve its public standing (Benoit, 1997). Meanwhile, RMP had the opportunity to learn from NV Energy's image crisis and use the suggested language preemptively. RMP could use the keywords to diminish the negative impacts of net metering or transcend their role as a utility company to one that focuses more on supporting the customer. Time and context appear critical for the differences in utility 
company communications and thus our final proposition is as follows:

P3: The use of recommended terms and language by NV Energy and RMP will differ due to net metering debates in Nevada and Utah occurring at different times relative to the release of The Future of Energy.

\section{METHODS}

We conducted qualitative case studies of two utility companies, NV Energy in Nevada and RMP in Utah. A case study methodology may include one or many approaches, such as interviews, observation, or analysis of relative documents. Most case study methods are qualitative in collection and analysis. Often, the detailed information gathered through a qualitative case study can provide insight into future quantitative research (Yin, 2013). Case studies are useful for our purposes as they enable us to conduct an in-depth investigation of the net-metering policy changes and discussions through distinct contexts, lenses, and data sources (Baxter and Jack, 2008). Here, the contextual condition of time is particularly important as the release of the communication handbook by Maslansky \& Partners occurred after changes to net-metering policies in Nevada but prior to analogous discussions in Utah. An advantage of conducting multiple case studies is the ability to compare the strategic use of language from the communication handbook that may have resulted from circumstantial differences. Similar to other qualitative studies, the data collection and analysis occurred concurrently (Yin, 2013).

For each case study, we identified three strategic key terms (universal, private, and private solar credits or subsidies) from The Future of Energy. These key terms were chosen because of their recommended use for net metering and solar energy. In our analyses of the websites and press releases, ${ }^{2}$ we looked for these terms and how the utility companies used them to position themselves in the net-metering debate. We chose to analyze websites and press releases because they are representations of the language used by utility companies in public relations and are routine ways in which corporations reach the media and their customers (Sleurs et al., 2003; Capriotti and Moreno, 2007). Press releases are often digitized and available on company websites, thus allowing organizations to bypass journalists and other media representatives. This affords companies and corporations more strategic control over their public image (Strobbe and Jacobs, 2005). Therefore, an analysis of press releases and website content related to net metering provide insight into the communication efforts of NV Energy and RMP. The inductive format of this comparative analysis aims to support propositions that may be extended beyond these two specific cases and tested in deductive case studies or quantitative analysis (Levy, 2008).

${ }^{2}$ Since August 31, 2017, NV Energy has restructured their website. Linked pages are different from those at the time of analysis, and some of the press releases included in this study are no longer publicly available.

\section{Analysis of Websites}

To conduct systematic qualitative analyses, we used the search feature on each utility company's home page to examine the use of each key term on the website. The search feature reviews the entire website for use of the keyword and reports where the term was found. We then examined each result for any mention of net metering. If the outcome used a key term and mentioned net metering, we included it in our analysis. The volume of results for each key term search on both websites is shown in Table $\mathbf{1}$. For consistency, both websites were analyzed on the same day, August 31, 2017. It should be noted that search results were composed of individual web pages, publicly available court proceedings, and marketing materials and did not include press releases. These were reviewed separately since each utility company had a complete collection of press releases available to the public. This allowed for a proportional analysis of press releases that contained keywords compared to the total number of press releases from each utility company.

\section{Analysis of Press Releases}

As press releases are distributed to newspapers and the community, we see them as artifacts distinct from the websites, which require a reader to actively seek out information. For this review, we examined all publicly available press releases on the websites of both utility companies. Press releases by NV Energy $(n=60)$ and RMP $(n=97)$ were available from January 1,2015 , to August 31, 2017, and January 1, 2016, to August 31, 2017, respectively. In each press release, we first searched for mentions of net metering. If a press release mentioned net metering, we then searched for the presence of key terms. If both net metering and a key term were used in a press release, it was included in analysis. Due to the availability of a census of press releases from each utility company, we were able to determine the proportion of press releases that mentioned net metering and, of those, the proportion that included the identified key terms (Table 2). Approximately, $18.3 \%$ of NV Energy press releases mentioned net metering, $73 \%$ of which used a handbook keyword. Meanwhile, 2\% of RMP press releases mentioned net metering and $1 \%$ used handbook keywords.

\section{RESULTS AND DISCUSSION}

In this study, we made several propositions: we posited that utility companies would use the language from The Future of Energy to strategically position themselves as pro-renewable energy (P1) and support their utility-scale projects as more equitable (P2). Our third proposition suggested that NV Energy and RMP would use handbook language differently due to the circumstances of the net-metering debate each utility company faced at the time

TABLE 1 | Frequency of use of each key term from The Future of Energy on utility company websites.

\begin{tabular}{lccc}
\hline & Universal & Private & Subsidy/credits \\
\hline NV Energy & 2 & 9 & 24 \\
Rocky Mountain Power & 2 & 17 & 3
\end{tabular}


TABLE 2 | Proportion of press releases by each utility company that mention net metering and frequency of key terms in them.

\begin{tabular}{lcccc}
\hline & $\begin{array}{c}\text { Proportion of } \\
\text { press releases } \\
\text { that mention net } \\
\text { metering }\end{array}$ & Universal & Private & $\begin{array}{c}\text { Subsidy/ } \\
\text { credits }\end{array}$ \\
\hline NV Energy $(n=60)$ & 18.3 & 2 & 4 & 2 \\
Rocky Mountain & 2.1 & 0 & 1 & 1 \\
Power $(n=97)$ & & & & \\
\hline
\end{tabular}

of the handbook release (P3). Before examining our results for each individual utility company, we describe the general findings of our analysis. Overall, we found that utility companies tended to use the terms universal and private to juxtapose utility-scale solar energy projects with those of residential solar power. For example, solar projects that originated from utility companies were described as universal and combined with the claim that these projects benefit all customers. In doing so, utility companies could position themselves as proponents of renewable energy. The language used around the term universal created inclusivity that grouped customers and companies against those who generate their own energy from residential solar installations. These private solar projects were described as external entities that do not contribute to the energy infrastructure of the community, such as when NV Energy referred to the "single class of private solar net metering customers" in a press release (NV Energy, 2017). The terms credit or subsidy were typically used to reinforce this contrast between universal- and private-renewable energy projects. We also found the latter terms to have financial connotations that evoke ideas of justice related to the unfair distribution of costs based on residential solar power generation.

Importantly, our findings highlight how utility companies strategically use the key terms to characterize utility-scale-renewable energy projects as a form of energy transition that aligns with one of the central tenets of the energy democracy movement, social justice. In doing so, utility companies emphasize universal solar projects as efforts that benefit communities in opposition to private solar installations that only benefit those individuals. In this context, the net metering at the retail rate is depicted as unfair to non-solar customers as it subsidizes residential solar energy generation.

\section{NV Energy}

We observed evidence for P1 and P2 in the use of language from the communication handbook on NV Energy's website (Table 1) and press releases (Table 2). In multiple instances on their website, customers with rooftop solar panels are referred to as private solar customers with private solar systems. By using the recommended terms private and universal on their website, NV Energy implicitly denigrates individual solar projects as an inequitable form of energy. Consequently, this makes their own action appear fair and reasonable. For example, a court docket on their website states that

NV Energy remains committed to offering renewable energy options to customers who are not willing or able to invest in private solar or other renewable energy options at their own premise or business, but who desire to meet their personal sustainability goals and/or further Nevada's green economy (Nevada Power Company, 2016a, p. 221).

By remaining committed to offering utility-scale solar power options to those who are financially limited, NV Energy appears to enable customers to participate in sustainable solutions to energy. Thus, this energy transition option appears more equitable than residential solar power. In another example, NV Energy states that the competitive bidding pricing of universalscale solar power ensures that customers are paying a fair price for solar photovoltaic energy (Nevada Power Company, 2016b). By highlighting the use of the terms private and universal, these examples situate NV Energy as supportive of renewable energy.

Moreover, we found 24 occurrences of the term subsidy or credit on NV Energy's website. This term was used to highlight the unfair distribution of costs that resulted from net metering. In a brochure, Net Metering 2016: Update and FAQs (NV Energy, 2016b), the company states, "Under the old net metering rules and rates, southern Nevada net metering customers were receiving an estimated $\$ 623$ annual subsidy per customer [...] If you do not have a rooftop solar system, you are part of a broad group of customers who pay that subsidy" (p. 2). Referring to the netmetering policy change that occurred in Nevada, the brochure goes on to state that "[w]ithout these new rules, that subsidy would have continued to grow." The emphasis on a "broad group of customers" who do not have rooftop solar panels highlights the social justice element of energy democracy and implies that those who have individual solar installations are benefiting from financial assistance in the form of subsidies and are, therefore, not paying their fair share.

To a lesser extent, we observed the use of these terms in press releases by NV Energy. While the website was analyzed after the distribution of the handbook, publicly available press releases both prior to and after handbook dissemination were examined. Interestingly, press releases published post-handbook circulation were the only ones that contained the key terms. As found on the website, the terms universal and private were used in tandem to juxtapose utility company projects and consumers with rooftop solar installations. A press release in October 2016 focused on the "appropriate value of excess energy credits provided to private rooftop solar customers" (NV Energy, 2016e). Private net-metering customers are singled out in later press releases (NV Energy, 2017), and such statements serve to isolate these individuals from the remainder of the community, i.e., those without rooftop solar. By contrast, the use of the term universal emphasizes a cleaner energy solution for all, such as in the Nevada's Energy Future: Key Principles document: “The price of universal scale solar energy has declined rapidly in the past five years" and this "[m]arket restructuring must not shift costs to vulnerable populations" (NV Energy, 2016a, p. 1).

A common charge that was frequently addressed in the communication efforts of NV Energy is whether changes to net metering would increase company profits. The utility company refutes this accusation on their website and in press releases. 
While utility companies do not earn a profit from electricity sales, they do earn a rate of return on investment. When utility companies invest in new power plants, the sale of energy provides financial returns. However, if individuals are able to generate their own energy, the ROI for utility companies decreases. In a January 2017 press release, NV Energy argued against a ruling by the PUCN to restrict changes to net metering, stating that the change "takes the savings that were intended for a larger customer base and directs them to this small subset of future solar net meter customers" (NV Energy, 2017, p. 1). This statement implies that the increase in costs resulted from subsidizing customers with rooftop solar installations.

\section{Rocky Mountain Power}

While we found support for P1 and P2 through the presence of language from The Future of Energy on RMP's website (Table 1), there was no evidence in the utility company's press releases related to net metering (Table 2). The website used the term private 17 times and contained a page designated solely for the discussion of private solar. This page stressed the considerable commitment required to install solar power due to large up-front costs and continued maintenance (Rocky Mountain Power, 2017). To focus on the pro-renewable energy position of the utility company, RMP stressed other options for customers, such as enrolling in a customer-supported renewable energy credit system or a subscriber solar power program. In both options, customers pay more money on their power bill to support utility company universal solar projects. The application of the handbook language allowed the utility company to appear supportive of solar and promote their company image:

Rocky Mountain Power's new Subscriber Solar program makes it easy for you to use solar energy without having to install rooftop solar panels. It's a simple, cost-effective way to support a more sustainable Utah and enjoy the benefits of solar energy with no rooftop required (Rocky Mountain Power, n.d., p. 1).

Many of the applications of The Future of Energy language focused on the equitable relationship between the utility company and their customers in opposition to other residential rooftop solar owners. A page on RMP's website contained a headline stating, "When it comes to solar net metering rates, it should be about fairness" (Rocky Mountain Power, n.d., p. 1). This implies an unequal foundation between customers with and without residential solar panels and situates the utility company as supportive of social justice. Moreover, the home page emphasized that net metering is a policy that is relevant only for consumers who have rooftop solar panels. According to RMP, these customers underpay the cost of providing amenities, including customer service and energy-grid maintenance. Those costs are shifted to customers who rely on the utility company for energy: "Rocky Mountain Power doesn't benefit from reducing the credit net metering customers receive for excess generation. The benefit would go to all other customers who would pay less on their bills" (Rocky Mountain Power, n.d., p. 1). While concurrently discrediting private rooftop systems, RMP asserts that rooftop solar customers save $35 \%$ on their energy bills compared to customers without residential solar panels. By stressing the financial inequality between rooftop solar panel owners and others, RMP positions itself as a protector of integrity in energy-making decisions.

While language from The Future of Energy was used on the RMP website to promote the reputation of the utility company and its relationship with customers in the netmetering debate, there was an overall lack of use in press releases. Of the 97 press releases publicly available on the website, only two mentioned net metering and, of those, only one used keywords from the communication handbook (Table 2). The sole press release that used handbook language was the initial announcement of RMP's proposed change in net-metering rates. It highlighted unfair distribution of costs and subsidies from non-rooftop solar customers to support private generation (Rocky Mountain Power, 2016). Yet, this was the only example that supported our proposition. Most of RMP's press releases focused on the community: awards, safety, and holidays. While this did not support our initial propositions regarding net metering, it does contribute to the overall strategic method to promote the utility company reputation and relationship with its customers.

\section{Differences between NV Energy and RMP}

Review of the utility companies' websites and press releases found evidence for P3. NV Energy proposed changes to net-metering policy in 2015, 1 year prior to the release of The Future of Energy, while RMP initiated net-metering discussions after publication of the handbook. Due to this timing, we expected that NV Energy would use handbook terminology in discussions about net metering as damage control, i.e., to repair their public image in the face of an offensive action (Benoit, 1997). In coping with the crisis, NV Energy would make corrective action claims and strategically try to reduce the offensiveness of the action. Meanwhile, we anticipated that RMP would use handbook language early and often in a preemptive manner, prior to the potential net-metering crisis, to reduce potential offensiveness and evade responsibility by placing it on individual solar customers. Both predictions reflect image restoration theory through different strategies. While both utility companies were anticipated to use keywords from The Future of Energy that manifest principles of the energy democracy movement, we suggested that the organizations would differ in strategy.

In our analysis, we found that both utility companies used language from the communication handbook in divergent ways on their websites. NV Energy used the terms energy and solar credits or subsidies 24 times; RMP mentioned private 17 times (Table 1). We believe that NV Energy's focus on the financial aspect of net metering was a reactive way to evade responsibility and repair their fractured image through justification of their actions as fair to all their customers (Benoit, 1997). Meanwhile, RMP's use of private repeatedly on the website positions rooftop solar customers in clear contrast to the utility company projects from which all customers benefit. This approach attempts to diminish the utility company's role in net metering and transfer blame to individual solar owners. This strategy both reduces offensiveness and evades responsibility (Benoit, 1997). 
Though both utility companies used language from The Future of Energy on their websites, the usage differed in public press releases. Almost $20 \%$ of NV energy press releases mentioned net metering, compared to only $2 \%$ of RMP press releases (Table 2). Directly following the release of the communication handbook, NV Energy incorporated the recommended language in their press releases. The early mention of net metering used jargon that The Future of Energy discouraged, such as "incentives to offset the installation costs of customer-owned distributed renewable generation including solar, wind and hydro" (NV Energy, 2016d, p. 1). All press releases that mentioned net metering following the distribution of the communication handbook used the suggested language to simplify a complex conversation. NV Energy's post hoc justification of their net-metering costs to customers resulted in the large use of handbook language.

While the lack of language from the communication handbook in RMP's press releases was unexpected, it echoed their overall effort to avoid discussions of net metering. Over half of the press releases instead focused on community actions that reflected the utility company as pro-renewable energy and committed to building relationships with their customers. The utility company actions reflect the preparation practices of image restoration theory by evading responsibility and focusing on other topics rather than an existing or future crisis (Benoit, 1997). By concentrating on community actions such as tree plantings and holiday celebrations, RMP could appear supportive of their customers and distance the company from discussions of a potential crisis. Our contrasting findings on NV Energy and RMP's websites and press releases provide evidence that the timing of release of The Future of Energy played an important role in how the utility companies used the suggested language.

\section{CONCLUSION}

A considerable disconnect exists between the dynamic world of distributed renewable energy and the current energy infrastructure. There are many key stakeholders involved in the energy sector, including those whose profits are tied to production, transmission, and distribution. The economic health of a utility company relies on energy sales and consistent ROI for energy projects. The increase in residential distributed energy reduces consumer reliance on utility companies by decreasing consumer demand for electricity and, therefore, the need for future investments by utility companies. Utilities consider net metering a solution to this complex problem, and discussions surrounding it allow for interesting and insightful case studies.

While utility companies may establish regulations on behalf of their customers, the energy democracy movement seeks to involve publics in energy decision making and emphasizes renewable energy transitions (Fairchild, 2017). It underscores the equitable awareness and involvement of all people in a democratic process. The energy democracy movement has critical implications for political, social, and democratic scholarship, yet as a developing area of analysis, the academic focus is on identifying foundational research directions. Studies thus far primarily accentuate positive aspects of energy democracy, such as civic change and public participation (Clarke, 2017; Stephens, 2017). The present study contributes to this growing body of knowledge by examining a theoretical gap between strategic communication and the energy democracy movement. We noted that there are important participants in the energy process who may view distributed renewable energy as prohibitive to their goals and therefore employ principles of the energy democracy movement in their communication efforts. Specifically, we sought to analyze how electric utility companies use the energy democracy movement as a strategy for communicating with their customers during net-metering discussions.

We reviewed the websites and press releases from two utility company case studies, NV Energy and RMP, for use of key terms derived from The Future of Energy: A Working Communication Guide for Discussion. The utility companies employed language from the communication handbook to emphasize their support for, and contributions to, equitable forms of renewable energy transition. Our case studies examined the use of language embodying the energy democracy movement and directly tied it to strategic communication and crisis communication efforts. By presenting utility-scale solar power options to those with financial or housing limitations, NV Energy and RMP seem to allow all customers to participate in renewable energy. Therefore, utility-scale energy options are perceived as more democratic and fair than individual options, primarily rooftop solar power. NV Energy and RMP adopted the terms private, universal, and credit or subsidy when discussing net metering to simplify a complex debate with a myriad of motivations and stakeholder positions into a simple dichotomy with one side for and the other against renewable energy. Markedly, the two utilities used The Future of Energy in different ways due to the circumstances surrounding the timing of the release of the communication handbook. While NV Energy used keywords from the handbook to repair their damaged image, RMP seldom mentioned net metering in their press releases and preemptively framed themselves positively in the context of net metering on their website. Both companies' efforts align with strategies of image restoration theory in an effort to minimize the effects of the crisis on their respective corporate images (Benoit, 1997).

While this study offers evidence of the strategic use of the communication handbook language to position utilities as pro-renewable energy in the topic of net metering, there are limitations. First, our sample consists of data from websites and press releases, which are communications that are controlled by the utility companies. Future research could expand the scope to include communication efforts over which the utility companies have limited control. One example is to conduct a content analysis of framing of utility company representative quotes in newspaper articles. This would address media content created by those outside of the utility company and offer a provocative comparison to the findings reported here. In addition, more corporations are taking to social media to connect with customers, and an analysis of social media content may prove to be insightful. While some studies review organizational image repair through social media, initial findings imply that traditional media have been more effective at repairing images (Liu and Kim, 2011; Moody, 2011). It may be that the static nature of image restoration theory is ill-suited to studying social media (Seeger and Padgett, 2010), and future 
scholarship should seek to examine energy democracy in this dynamic communication environment. As this is one of the first studies to address strategic communication efforts by utility companies, we felt that websites and press releases were appropriate foundational representations of utility company communications (Sleurs et al., 2003; Capriotti and Moreno, 2007).

Furthermore, while the timing and context of the utility companies' net-metering conversations are important, there may be other factors influencing the differences between the two cases. Utility companies are unique organizations that have distinct hierarchical structures and internal correspondence practices, which inform their external communication efforts. The present work does not analyze these potential latent attributes as they are beyond the scope of this project. However, an internal review of organizational practices would be a complementary avenue for future research. Finally, this review focuses on the frequency of keywords from The Future of Energy; yet, prevalence of the keywords does not necessarily indicate intention. While we show the proportion of keyword use in relation to other topics in press releases, we were unable to quantify keyword use through website communication. Since websites are constantly updating and definitive boundaries can be uncertain, there is no concrete total amount of data with which to compare keyword use and calculate proportions. As this is a preliminary study of energy democracy as strategic communication, we feel that the frequency of use, as well as the proportion of press releases, is more than adequate as a benchmark on which future research can build.

This case study analyzed artifacts within the specific proposed time boundaries; yet, strategic communication often takes place over extended periods of time. We decided on the time frame of this study based on the accessibility of press releases on each of the utility company websites. Prospective research should expand

\section{REFERENCES}

Atkinson, S. E., and Halvorsen, R. (1986). The relative efficiency of public and private firms in a regulated environment: the case of US electric utilities. J. Public Econ. 29, 281-294. doi:10.1016/0047-2727(86)90030-7

Avery, E. J., Lariscy, R. W., Kim, S., and Hocke, T. (2010). A quantitative review of crisis communication research in public relations from 1991 to 2009. Publ. Relat Rev. 36, 190-192. doi:10.1016/j.pubrev.2010.01.001

Barwick, M., Phipps, D., Myers, G., Johnny, M., and Coriandoli, R. (2014). Knowledge translation and strategic communications: unpacking differences and similarities for scholarly and research communications. Scholar. Res. Commun. 5, 1-14. doi:10.22230/src.2014v5n3a175

Baxter, P., and Jack, S. (2008). Qualitative case study methodology: study design and implementation for novice researchers. Qual. Rep. 13, 544-559.

Bell, S. E., and York, R. (2010). Community economic identity: the coal industry and ideology construction in West Virginia. Rural Soc. 75, 111-143. doi:10.1111/j.1549-0831.2009.00004.x

Benoit, W. L. (1997). Image repair discourse and crisis communication. Publ. Relat. Rev. 23, 177-186. doi:10.1016/S0363-8111(97)90023-0

Benoit, W. L. (2000). Another visit to the theory of image restoration strategies. Commun. Q. 48, 40-43. doi:10.1080/01463370009385578

Bostdorff, D. M., and Vibbert, S. L. (1994). Values advocacy: enhancing organizational images, deflecting public criticism, and grounding future arguments. Publ. Relat. Rev. 20, 141-158. doi:10.1016/0363-8111(94)90055-8

Botan, C. (1997). Ethics in strategic communication campaigns: the case for a new approach to public relations. J. Bus. Commun. 34, 188-202. doi:10.1177/ 002194369703400205 on the period of analysis to observe dynamic change over greater lengths of time. In addition, an extended study could incorporate more utility companies for analysis. Since over half of all states redesigned their net-metering policies in recent years, there is potential for broader comparisons (Carley and Davies, 2016). This study focused on NV Energy and RMP due to their involvement in intense net-metering debates around the time of the communication handbook release. A narrow investigation allowed for comparison and identification of similarities and differences of these cases. As this study was exploratory, future analysis should build upon this research by examining other utility companies that are enmeshed in net-metering debates.

The energy industry is at a transitional crossroads, partly due to the rapid increase in distributed renewable energy. How electric utility companies choose to communicate about issues related to renewables will play a major role in defining future energy policies. Here, we examined how energy democracy was used as a form of strategic communication through a qualitative analysis of the use of key terms from The Future of Energy handbook. Using the handbook recommendations, NV Energy and RMP emphasized their pro-renewable energy position and framed their net-metering policies as socially just positions in energy decision making. This study contributes to a growing research agenda in energy democracy and displays the potential use of the energy democracy movement as a form of strategic communication.

\section{AUTHOR CONTRIBUTIONS}

MM was the lead author of this piece and conducted all research. SY acted as the second author and editor.

Braithwait, S., and Eakin, K. (2002). The Role of Demand Response in Electric Power Market Design. Edison Electric Institute. Available at: http://assets.fiercemarkets.net/public/smartgridnews/sgnr_2007_12014.pdf

Burns, J. P., and Bruner, M. S. (2000). Revisiting the theory of image restoration strategies. Commun. Q. 48, 27-39. doi:10.1080/01463370009385577

Capriotti, P., and Moreno, Á (2007). Corporate citizenship and public relations: the importance and interactivity of social responsibility issues on corporate websites. Publ. Relat. Rev. 33, 84-91. doi:10.1016/j.pubrev.2006.11.012

Carley, S., and Davies, L. L. (2016). Nevada's Net Energy Metering Experience: The Making of a Policy Eclipse? Rochester, NY: Social Science Research Network. (SSRN Scholarly Paper No. ID 2882918).

Clarke, C. E. (2017). "Incorporating citizen engagement in energy development decision," in Presented at the Energy Democracy Symposium (Salt Lake City, UT).

Coombs, W. T. (2015). The value of communication during a crisis: insights from strategic communication research. Bus. Horiz. 58, 141-148. doi:10.1016/j. bushor.2014.10.003

Cornelissen, J., and Cornelissen, J. P. (2017). Corporate Communication: A Guide to Theory and Practice. SAGE. Available at: https://books.google. com/books?hl=en \&lr=\&id=Ju60DQAAQBAJ\&oi=fnd\&pg=PP1\&d$\mathrm{q}=$ corporate + communication + about + crisis\&ots $=$ eVfOUiXg5Q\&sig $=$ v0WwrtHIc_1cKFkKtIO6Y1VlOiI

Cox, J. R. (2010). Beyond frames: recovering the strategic in climate communication. Environ. Commun. 4, 122-133. doi:10.1080/17524030903516555

Cox, R. (2007). Nature's "crisis disciplines": does environmental communication have an ethical duty? Environ. Commun. 1, 5-20. doi:10.1080/17524030701333948

Doris, E., Booth, S., and Hockett, S. (2009). Net Metering Policy Development in Minnesota: Overview of Trends in Nationwide Policy Development and 
Implications of Increasing the Eligible System Size Cap. Lakewood, CO: National Renewable Energy Laboratory.

Endres, D., Cozen, B., Barnett, J., O'Byrne, M., and Peterson, T. (2016). Communicating energy in a climate (of) crisis. Ann. Int. Commun. Assoc. 40, 419-447. doi:10.1080/23808985.2015.11735267

Faber, D. (2008). Capitalizing on Environmental Injustice: The Polluter-Industrial Complex in the Age of Globalization. Rowman \& Littlefield Publishers. Available at:https://books.google.com/books?hl=en\&lr=\&id=9bq-AAAAQBAJ\&oi= fnd \&pg $=$ PR7\&dq=Nature $+\% E 2 \% 80 \% 99+$ s+meaning:+Capitalizing + on + environmental+injustice: + The + polluter-industrial+complex+ in +the+age+of+globalization\&ots=MziGSWlhos\&sig=nQO5X2XQ_M_ n85vwgf4fQ992Fv8

Faden, V. J. (2000). Net metering of renewable energy: how traditional electricity suppliers fight to keep you in the dark. Widener J. Pub. L. 10, 109-134.

Fairchild, D. (2017). Energy Democracy: Advancing Equity in Clean Energy Solutions. Washington, DC: Island Press.

Fang, X., Misra, S., Xue, G., and Yang, D. (2012). Smart grid-the new and improved power grid: a survey. IEEE Commun. Surv. Tutorials 14, 944-980. doi:10.1109/ SURV.2011.101911.00087

Farrell, J. (2014). Minnesota's Value of Solar. Institute for Local Self-Reliance. Available at: http://ilsr.org/wp-content/uploads/2014/04/MN-Value-of-Solarfrom-ILSR.pdf

Forsyth, T. L., Pedden, M., and Gagliano, T. (2002). The Effects of Net Metering on the Use of Small-Scale Wind Systems in the United States. National Renewable Energy Laboratory. Available at: http://www.nrel.gov/docs/fy03osti/32471.pdf

Giancatarino, A. (2012). Energy Democracy: Supporting Community Innovation. New York, NY: The Center for Social Inclusion. Available at: http://www. centerforsocialinclusion.org/wp-content/uploads/2012/02/EnergyDemocracy-Supporting-Community-Innovation.pdf

Hanan, J. S. (2013). The ecology of empire: Wal-Mart's rhetoric of environmental stewardship and the constitutive power of the multitude. Environ. Commun. 7, 529-547. doi:10.1080/17524032.2013.822011

Harlow, W. F., Brantley, B. C., and Harlow, R. M. (2011). BP initial image repair strategies after the Deepwater Horizon spill. Publ. Relat. Rev. 37, 80-83. doi:10.1016/j.pubrev.2010.11.005

Holtzhausen, D. (2008). "Strategic communication," in The International Encyclopedia of Communication (Hoboken, NJ: John Wiley \& Sons, Ltd).

Kroposki, B., Margolis, R., Kuswa, G., Torres, J., Bower, W., Key, T., et al. (2008). Renewable Systems Interconnection: Executive Summary. Golden, CO: National Renewable Energy Laboratory (NREL). Available at: http://www.osti.gov/ scitech/biblio/924646

Levy, J. S. (2008). Case studies: types, designs, and logics of inference. Conf. Manage. Peace Sci. 25, 1-18. doi:10.1080/07388940701860318

Liu, B. F. (2007). President Bush's major post-Katrina speeches: enhancing image repair discourse theory applied to the public sector. Publ. Relat. Rev. 33, 40-48. doi:10.1016/j.pubrev.2006.11.003

Liu, B. F., and Fraustino, J. D. (2014). Beyond image repair: suggestions for crisis communication theory development. Publ. Relat. Rev. 40, 543-546. doi:10.1016/j.pubrev.2014.04.004

Liu, B. F., and Kim, S. (2011). How organizations framed the $2009 \mathrm{H} 1 \mathrm{~N} 1$ pandemic via social and traditional media: implications for US health communicators. Publ. Relat. Rev. 37, 233-244. doi:10.1016/j.pubrev.2011.03.005

Maslansky and Partners. (2016). The Future of Energy: A Working Communication Guide for Discussion (Handbook). New York, NY: Edison Electric Institute.

Matz, J., and Renfrew, D. (2015). Selling "Fracking": energy in depth and the Marcellus Shale. Environ. Commun. 9, 288-306. doi:10.1080/17524032.2014. 929157

Miller, B. M., and Lellis, J. (2016). Audience response to values-based marketplace advocacy by the fossil fuel industries. Environ. Commun. 10, 249-268. doi:10.1 080/17524032.2014.993414

Moody, M. (2011). Jon and Kate Plus 8: a case study of social media and image repair tactics. Publ. Relat. Rev. 37, 405-414. doi:10.1016/j.pubrev.2011.06.004

Muro, M., and Saha, D. (2016). Rooftop Solar: Net Metering Is a Net Benefit. (No. Series paper 91). Available at: https://www.brookings.edu/research/ rooftop-solar-net-metering-is-a-net-benefit/

Nevada Power Company. (2016a). NV Energy Seeking Approval of the Second Amendment to Its 2016-2035 Integrated Resource Plan. No. 16-08 (Public Utilities Commission of Nevada October 1, 2016). Available at: https://www.nvenergy.com/publish/content/dam/nvenergy/brochures_arch/ about-nvenergy/rates-regulatory/recent-regulatory-filings/south/irp/ NPC_IRP_Amendment_Volume_2.pdf

Nevada Power Company. (2016b). NV Energy Before The Public Utilities Commission of Nevada. No. 17-06 (Public Utilities Commission of Nevada December 31, 2016). Available at: https://www.nvenergy.com/publish/content/ dam/nvenergy/brochures_arch/about-nvenergy/rates-regulatory/recentregulatory-filings/south/grc/NPC-GRC-Volume-11.pdf

NV Energy. (2016a). Nevada's Energy Future: Key Principles. NV Energy. Available at:https://www.nvenergy.com/publish/content/dam/nvenergy/brochures_ arch/about-nvenergy/news/news-releases/key-principles.pdf

NV Energy. (2016b). NV Energy Net Metering 2016 Update and FAQs. NV Energy. Available at: https://www.nvenergy.com/publish/content/dam/nvenergy/ bill_inserts/2016/03_mar/Net-Metering-2016-Update-and-FAQs_26_31.pdf

NV Energy. (2016c). NV Energy Takes Strong Next Step to Grandfather Net Metering Customers. Available at: https://www.nvenergy.com/renewablesenvironment/ solar/nem-update-20170727.cfm

NV Energy. (2016d). NV Energy Makes Required Annual Deferred Energy Northern Filing. Available at: https://www.nvenergy.com/about-nvenergy/news/newsreleases/nv-energy-makes-required-annual-deferred-energy-northernfiling

NV Energy. (2016e). NV Energy Announces Agreement on Price Reduction for Northern Nevada Electric and Gas Customers. Available at: https://www. nvenergy.com/company/mediaroom/newsdetail.cfm?n=136952

NV Energy. (2017). NV Energy Asks Public Utilities Commission To Reconsider Decision To Reallocate \$2.92 Million Annual Rate Savings To New Solar Net Metering Customers. Available at: https://nvenergy.mediaroom.com/index. php? $=8838$ \&item $=136941$

O'Donoghue, A. (2017). State Utility Commission Weighs Approval of Rooftop Solar Agreement. Deseret News. Available at: https://www.deseretnews.com/ article/865689063/State-utility-commission-weighs-approval-of-rooftopsolar-agreement.html

Olaniran, B. A., and Williams, D. E. (2008). Applying anticipatory and relational perspectives to the Nigerian delta region oil crisis. Publ. Relat. Rev. 34, 57-59. doi:10.1016/j.pubrev.2007.11.005

Penrod, E. (2017). Rocky Mountain Power, Solar Advocates, Reach a Deal on an Alternative to Utility's Net-metering Program. The Salt Lake Tribune. Availableat:https://www.sltrib.com/news/environment/2017/08/29/rockymountain-power-solar-advocates-reach-a-deal-on-an-alternative-to-utilitysnet-metering-program/

Pezzullo, P. C. (2017). "On math, stories, \& community engagement: lessons from Boulder's climate action plan," in Presented at the Energy Democracy Symposium (Salt Lake City, UT).

Price, S., Pickrell, K., Kahn-Lang, J., Ming, Z., and Chait, M. (2014). Nevada Net Energy Metering Impacts Evaluation. Energy+Environmental Economics. Availableat:http://puc.nv.gov/uploadedFiles/pucnvgov/Content/About/ Media_Outreach/Announcements/Announcements/E3\%20PUCN\%20 NEM\%20Report\%202014.pdf?pdf=Net-Metering-Study

Ramos-Real, F. J. (2005). Cost functions and the electric utility industry. A contribution to the debate on deregulation. Energy Policy 33, 69-87. doi:10.1016/ S0301-4215(03)00200-3

Rocky Mountain Power. (2016). Study Supports New Rate for Rooftop Solar Customers. Available at: https://www.rockymountainpower.net/about/nr/ nr2016/proposed-net-metering-changes.html

Rocky Mountain Power. (2017). Private Generation. Available at: https://www. rockymountainpower.net/env/nmcg.html

Rokeach, M. (1968). Beliefs, Attitudes and Values: A Theory of Organization and Change. Available at: http://www.citeulike.org/group/794/article/235562

Schwarze, S. (2007). Environmental communication as a discipline of crisis. Environ. Commun. 1, 87-98. doi:10.1080/17524030701334326

Seeger, M. W., and Padgett, D. R. G. (2010). From image restoration to renewal: approaches to understanding postcrisis communication. Rev. Commun. 10, 127-141. doi:10.1080/15358590903545263

Sleurs, K., Jacobs, G., and Van Waes, L. (2003). Constructing press releases, constructing quotations: a case study. J. Sociolinguistics 7, 192-212. doi:10.1111/1467-9481.00219

Sproule, J. M. (1988). The new managerial rhetoric and the old criticism. Q. J. Speech 74, 468-486. doi:10.1080/00335638809383854 
Steiner, F. (2000). Regulation, Industry Structure, and Performance in the Electricity Supply Industry. Rochester, NY: Social Science Research Network. (SSRN Scholarly Paper No. ID 223648).

Stephens, J. C. (2017). "Strengthening resilience by redistributing power: energy democracy, gender, diversity, and inclusion in the renewable energy transition," in Presented at the Energy Democracy Symposium (Salt Lake City, UT).

Stephens, J. C., Wilson, E. J., and Peterson, T. R. (2015). Smart Grid (R) Evolution. Cambridge University Press. Available at: http://books.google.com/ books?hl=en\&lr=\&id=LAREBgAAQBAJ\&oi=fnd\&pg=PR11\&dq=info:ts4t20qMVWwJ:scholar.google.com\&ots=bpLw7AkfxN\&sig=pwXHJ3rw rtxVRAdJNgI5jC6sds

Strobbe, I., and Jacobs, G. (2005). E-releases: a view from linguistic pragmatics. Publ. Relat. Rev. 31, 289-291. doi:10.1016/j.pubrev.2005.02.009

Toth, E. L. (1986). Broadening research in public affairs. Publ. Relat. Rev. 12, 27-36. doi:10.1016/S0363-8111(86)80024-8

Weiner, J. (2015). Price of Solar Energy in the United States Has Fallen to 5 $\$ / k W h$ on Average. Berkeley Lab. Available at: http://newscenter.lbl.gov/2015/09/30/ price-of-solar-energy-in-the-united-states-has-fallen-to-5\%c2\%a2kwh-onaverage/

Yin, R. K. (2013). Case Study Research: Design and Methods. SAGE. Available at:https://books.google.com/books?hl=en\&lr=\&id=OgyqBAAAQBA$\mathrm{J} \&$ oi $=$ fnd \&pg $=$ PT243\&dq $=$ Case + study+research:+Design + and + meth ods\&ots $=$ FbE3p7m46i\&sig=eoDBBV3p-gSaK6UEuJbKn9Y8czw

Conflict of Interest Statement: The authors declare that the research was conducted in the absence of any commercial or financial relationships that could be construed as a potential conflict of interest.

Copyright (C) 2018 McKasy and Yeo. This is an open-access article distributed under the terms of the Creative Commons Attribution License (CC BY). The use, distribution or reproduction in other forums is permitted, provided the original author(s) and the copyright owner are credited and that the original publication in this journal is cited, in accordance with accepted academic practice. No use, distribution or reproduction is permitted which does not comply with these terms. 